posterior placenta-10 of which occur in the series-may produce insufficient heat emission to be detectable through the anterior abdominal wall. However, no better results are obtained in locating the anteriorly placed placenta.

Four cases of placenta praevia are included in the series. Initially, the absence, in placenta praevia cases, of an identifiable placental site on thermography was thought to be significant. However, in two of the cases subsequently demonstrated to be anterior type I placenta praevia, where the bulk of the placenta is in the body of the uterus, no site was demonstrated by thermography (Fig. 4).

Although confirmation of the placental site was not obtained, interpretation of the thermographic findings of the remaining patients, who had vaginal deliveries without third-stage complications necessitating manual removal, yielded results similar to those described above.

\section{Conclusions}

The Pyroscan is an expensive piece of apparatus that operates adequately only under ideal conditions, which are sometimes not easy to attain, and which, though not unpleasant, are not comfortable for the patient. A supply of liquid nitrogen, which requires constant replenishment, is essential in order to cool the heat-sensitive cell of the apparatus, though the latest models are now fitted with an automatic liquid-nitrogentransfer device.

Despite prolonged trial with the technical assistance of the manufacturers, it was found impossible to obtain thermographs which were of any value in determining the placental site.

An infra-red scanning apparatus, identical to the one used in this study, has been in use at the Jefferson Hospital in Philadelphia (personal communication). A lower ambient temperature $\left(18^{\circ}\right.$ C.) may have contributed to the more promising results in the series performed there.

Refinements in the apparatus may lead to an improvement in the quality of the thermographs, but until this advance is made identification of the placental site by thermography is unlikely to prove a useful obstetrical investigation.

Other applications of thermography were briefly tried while the apparatus was available. In the investigation of vascular occlusion-venous and arterial-it is of undoubted value, as it is in the investigation of breast lesions. It is considered that there is insufficient emission of heat from the placenta, even when it is situated anteriorly, to produce, on the surface of the abdominal wall, a heat pattern which the apparatus can detect.

\section{Summary}

The application of thermography in locating the placental site is investigated. The Pyroscan and its method of use are described. Of 150 patients scanned 21 were delivered by caesarean section and two had manual removal of placenta. The results show that thermography cannot be relied upon to predict the placental site accurately.

I wish to thank Professor Ian Donald for his constant help and encouragement. Also I am indebted to S. Smith \& Sons (England) Ltd. for the loan of the Pyroscan apparatus, and particularly grateful to Mr. Ashley Letts, of Smith \& Sons Ltd., for his technical advice.

\section{REFERENCES}

Barnes, R. B. (1963). Science, 140, 870.

Birnbaum, S. J., and Kliot, D. A. (1965). Obstet. and Gynec., 25, 515. Cade, C. M. (1964). Ann. N.Y. Acad. Sci., 121, 71.

Lawson, R. N. (1956). Canad. med. Ass. Ұ., 75, 309.

Lloyd Williams, K., Lloyd Williams, F., and Handley, R. S. (1960) Lancet, 2, 1378 .

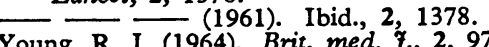

\title{
Staphylococcal Colonization of the Rectum in the Newborn
}

\author{
DINAH BARRIE,* M.B., B.S.
}

Despite the frequent isolation of Staphylococcus aureus from stool cultures of newborn infants, the finding is not always reported and its significance is uncertain. For instance, in a three-months pilot survey a moderate or heavy growth of Staph. aureus was cultured from stool specimens of 26 out of 113 infants suffering from diarrhoea, failure to thrive, and loss of weight. The present investigation was undertaken to study staphylococcal invasion of the rectum in the newborn, its relation to colonization in other sites, and its clinical significance.

\section{Materials and Methods}

Ninety-two randomly selected babies were tested on 447 occasions over the course of six months, during which time approximately 500 babies were born in the unit. The first 50 babies were examined daily from birth until discharged home, mostly on the eighth day. The remainder were examined on isolated occasions up to 7 weeks of age.

Specimens were obtained from the umbilicus, perineum, and rectum. A special device was made for taking high rectal

\footnotetext{
* Department of Clinical Microbiology, Louis Jenner Laboratories, St.
} Thomas's Hospital and Medical School, London. swabs without contamination from the perianal skin (Fig. 1). This consisted of a piece of tissue-paper, folded over a short piece of glass tubing and secured loosely with a strip of adhesive tape. The whole was enclosed in a test-tube, sealed with cottonwool, and sterilized by autoclaving. Samples were obtained by inserting the covered end of the tube, lubricated with sterile petroleum jelly, into the rectum. With the paper sheath held in one hand the tube was advanced so that it perforated the paper and projected approximately $1 \mathrm{~cm}$. beyond the torn edges. An ordinary throat swab was then passed down the tube to sample meconium or stool. All swabs were plated direct on to salt mannite agar and incubated at $37^{\circ} \mathrm{C}$. for 48 hours. Staph. aureus was recognized by its colony appearance, mannite fermentation, and tube coagulase activity. Antibiotic sensitivity patterns were determined by the multi-disc method, and phage-typing was carried out by the method of Williams and Rippon (1952).



FIG. 1.-Rectal sampling device. 
Rectal temperatures were recorded on all babies at the time of the first bath, usually within a few hours of birth, and thereafter only if indicated. A communal thermometer, kept in $5 \%$ carbolic solution, was used. The umbilical cords, occluded by rubber bands, were powdered daily with $1 \%$ hexachlorophane and left exposed. Thirteen of the babies received prophylactic intramuscular penicillin and streptomycin on account of prolonged rupture of the membranes, offensive liquor, or meconium aspiration. Feeding from the breast or bottle was usually begun in the first 12 hours, but all breastfed babies were given an occasional bottle-feed of milk or glucose. Bottles and teats were sterilized in Milton solution.

\section{Resuits}

Incidence of Colonization.-The overall incidence of umbilical, perineal, and rectal colonization is shown in Fig. 2. Rectal colonization occurred in $48 \%$ of the babies by the eighth day, and $10 \%$ were already positive within 24 hours of birth. Of 44 babies from whom positive rectal cultures were obtained the growth was moderate or heavy in 25 and scanty in the remainder. The growths tended to become heavier as the babies became older. The three sites were not colonized at the same rate or to the same extent: 13 babies developed colonization in one site only, 14 in two sites, 32 in all three sites, and 34 in none. The number of positive specimens tended to increase up to the seventh day, after which a decrease in umbilical colonization oscurred, presumably due to separation of the cord and drying of the umbilicus.

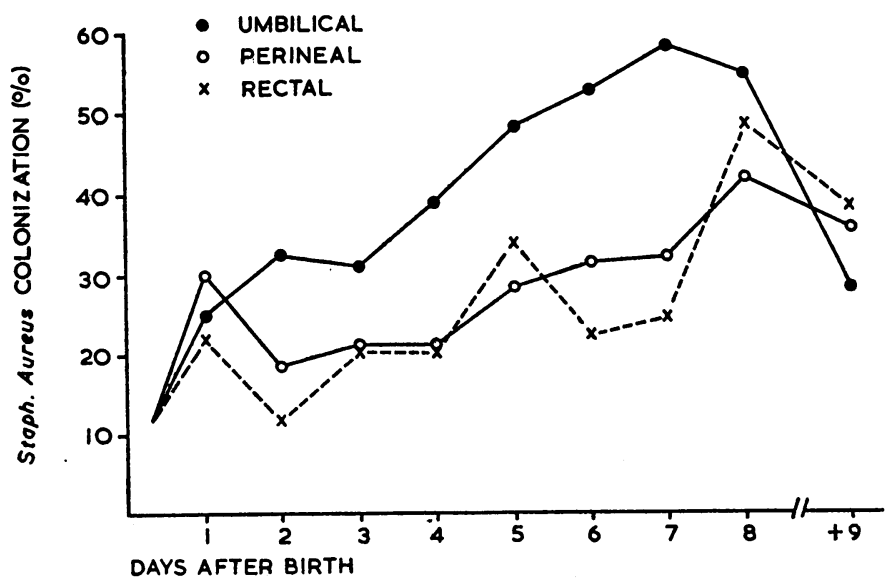

Frg. 2.-Incidence of umbilical, perineal, and rectal colonization.

Weight Gain and Feeding.-The presence of Staph. aureus in the stools was not associated with abnormal weight loss, failure to regain birth weight (Table I), or undue clinical sepsis. However, colonization of all three sites was more common and developed earlier in breast-fed babies (Table II).

TABLE I.-Rectal Colonization and Weight on Eighth Day

\begin{tabular}{|c|c|c|}
\hline \multirow{2}{*}{ Babies } & \multicolumn{2}{|c|}{ Staph. aureus } \\
\hline & Positive & Negative \\
\hline $\begin{array}{l}\text { Number } \ldots \\
\text { Birth weight not regained } \\
\text { Ounces (g.) below birth weight } \ldots\end{array}$ & $\begin{array}{l}44 \\
30 \% \\
4 \cdot 6(130 \mathrm{~g} .)\end{array}$ & $\begin{array}{c}48 \\
34 \% \\
3 \cdot 9(110 \mathrm{~g} .)\end{array}$ \\
\hline
\end{tabular}

TABLE II.-Comparison of Colonization in Breast-fed and Bottle-fed

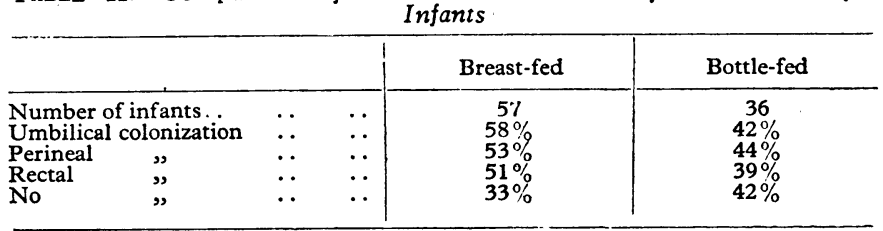

Antibiotic Therapy.-Thirteen babies who received penicillin and streptomycin for the first three days showed reduced colonization of all three sites as late as the twelfth day, and eight of the 13 had not developed rectal colonization up to the day of discharge.

Antibiotic Sensivity Pattern.-The antibiotic resistance of positive cultures at the various sites is shown in Table III; $85 \%$ to $92 \%$ of the staphylococci were resistant to penicillin. Close similarity was found in the pattern between perineal and rectal staphylococci, these showing a high incidence of multiresistance, whereas a different pattern emerged in umbilical staphylococci.

TABLE III.-Antibiotic Resistance of Staphylococci Isolated

\begin{tabular}{ccc|c|c|c}
\hline & & & Umbilicus & Perineum & Rectum \\
\hline Penicillin-sensitive & $\ldots$ & $\ldots$ & $15 \%$ & $8 \%$ & $10 \%$ \\
resistant & $\ldots$ &. & $67 \%$ & $59 \%$ & $58 \%$ \\
Multiple resistance & $\cdots$ &. & $17 \%$ & $33 \%$ & $31 \%$ \\
\hline
\end{tabular}

Phage Types.-A similarity between rectal and perineal staphylococci was also evident in the phage-type results (Table IV). The majority belonged to group I or were non-typable. The epidemic strain $80 / 81$ was isolated on only three occasions, twice from the umbilicus and once from the rectum.

\begin{tabular}{|c|c|c|c|c|c|c|}
\hline \multirow{2}{*}{ Site } & \multicolumn{6}{|c|}{ Phage-type Groups* } \\
\hline & $\mathbf{I}$ & II & III & IV & $\mathbf{V}$ & $\begin{array}{c}\text { Non- } \\
\text { typable }\end{array}$ \\
\hline $\begin{array}{l}\text { Umbilicus } \\
\text { Perineum } \\
\text { Rectum }\end{array}$ & $\begin{array}{l}41 \% \\
25 \% \\
25 \%\end{array}$ & $\begin{array}{l}\overline{1} \% \\
2 \%\end{array}$ & $\begin{array}{l}8 \% \\
6 \% \\
9 \%\end{array}$ & $\begin{array}{l}-\overline{2 \%} \\
3 \%\end{array}$ & $\begin{array}{r}8 \% \\
16 \% \\
17 \%\end{array}$ & $\begin{array}{l}44 \% \\
49 \% \\
42 \%\end{array}$ \\
\hline
\end{tabular}
* Group I: Phages 29, 52, 52A, 79, 80, 81. Group II: Phages 3A, 3B, 3C, 55,
71. Group III: Phages 6, 7, 42E, 47, 53, 54, 187, 75, 77. Group IV: Phage 42D. Group V: Phage 83A.

\section{Discussion}

The incidence of Staph. aureus in the stools of newborn infants has been variously reported as between 0 and $88 \%$, depending on the numbers in each series, their ages, and the bacteriological techniques used (Todd, 1922; Crowley and Downie, 1941 ; Duncan and Walker, 1942 ; Martyn, 1949 ; Buttiaux and Pierret, 1949 ; Duff, Murray, and Prissick, 1953).

On taking rectal specimens the problem is to avoid contamination from the perianal skin. Though false-positive rectal cultures were reduced to a minimum by the special technique used in the present investigation, it was theoretically possible for organisms to be introduced during insertion of the tube, resulting in a positive rectal culture on a subsequent occasion. In practice this was probably not important, as in most cases regative rectal specimens repeated on subsequent days remained negative.

The presence of staphylococci in the rectum must indicate either ingestion, thus implying passage through the entire alimentary tract, or retrograde spread from the perianal skin. It is perhaps significant that a higher percentage of breast-fed babies' developed rectal colonization. The incidence of Staph. aureus in normal breast milk is around $3 \%$ (Foster and Harris, 1960), to which must be added the considerable factor of skin carriage on the nipple, which may be as high as $90 \%$ (Duncan and Walker, 1942). Close handling, especially by the mothers, is an important cause of colonization in both breastfed and bottle-fed babies. Although retrograde spread of staphylococci from perineum to rectum cannot be discounted, the similar antibiotic resistance and phage-type pattern of staphylococci from these two sites may equally well be due to secondary spread from stool to perineum.

It is generally agreed that staphylococcal invasion of babies in the nursery may be caused by airborne spread, by direct 
contact, or by contaminated objects. According to Jellard (1957), the main reservoirs of this organism are (a) open lesions in the mothers, babies, or staff ; $(b)$ adult skin and nasal carriers; and $(c)$ the babies themselves, the umbilical cord being one of the principal sites. More than $80 \%$ of hospital-born infants are said to develop umbilical colonization by staphylococci at the fourth day (Fairchild, Graber, Vogel, and Ingersoll, 1958). In this respect the presence of the organism in the babies' stools has not been emphasized. Since staphylococci were cultured from the stools in nearly $50 \%$ of babies by the eighth day, the stools must be regarded as a potential reservoir of infection to which appropriate action must be directed during nursery outbreaks of staphylococcal sepsis.

\section{Summary}

Rectal colonization by Staph. aureus occurred in $48 \%$ of 92 normal newborn infants by the eighth day, and was not asso- ciated with any gastro-intestinal disturbance. The finding of Staph. aureus in stool cultures from infants with diarrhoea should be regarded as incidental, unless shown to be caused by an epidemic strain. However, the prevalence of this organism in the stools may be a significant reservoir of staphylococcal spread in nursery infections.

\section{REFERENCES}

Buttiaux, R., and Pierret, J. (1949). Ann. Inst. Pasteur, 76, 480.

Crowley, N., Downie, A. W., Fulton, F., and Wilson, G. S. (1941). Lancet, $2,590$. Duff, G. L., Murray, E. G. D., and Prissick, F. H. (1953). Amer. F. med.

Duncan, J. T., and Walker, J. (1942). f. Hyg. (Lond.), 42, 474.

Fairchild, J. P., Graber, C. D., Vogel, E. H., and Ingersoll, R. L. (1958). F. Pediat., 53, 538 .

Foster, W. D., and Harris, R. E. (1960). F. Obstet. Gynaec. Brit. Cwlth, 67, 463.

Jellard,' J. (1957). Brit. med. f., 1, 925.

Martyn, G. (1949). Ibid., 1, 710.

Todd, E. W. (1922). ₹. Hyg. (Lond.), 21, 37

Williams, R. E. O., and Rippon, J. E.'(1952). Ibid., 50, 320.

\title{
Infection with Animal Helminths as a Factor in Causing Poliomyelitis and Epilepsy
}

\author{
A. W. WOODRUFF, * M.D., PH.D., F.R.C.P., F.R.C.P.ED., D.T.M.\&H. \\ B. BISSERU,† M.SC., PH.D., M.B., M.R.C.P.ED., D.T.M.\&H., D.OBST.R.C.O.G. \\ J. C. BOWE $\ddagger$ M.D., F.R.C.P.ED., D.P.H.
}

Brit. med. F., 1966, 1, 1576-1579

Earlier work demonstrated that in Britain, as in some countries overseas, the possibility of acquiring infection with Toxocara canis or $T$. cati is considerable and that this infection may account for some cases of eosinophilia and allergic states of otherwise undetermined origin (Woodruff and Thacker, 1964). In that earlier paper the possibility was discussed that larvae, in migrating, may be capable of carrying virus from the intestine to the brain and other tissues, and reference was made to the post-mortem finding by Beautyman and Woolf (1951) of a larva, almost certainly $T$. canis, in the brain of a child who had died from poliomyelitis. It was also deduced that the seeming predilection for toxocariasis to affect the eye is more apparent than real and does not indicate the full frequency with which this infection is contracted by man. The probability is that, as the eye is a relatively small organ, other larger structures are invaded more often than it is, but that invasion of the eye, by giving rise to visual disturbance, leads more commonly to medical advice being sought and the diagnosis being made than does invasion of such organs as the liver or even the brain. From involvement of the latter much less easily diagnosed symptoms are likely to arise.

Sprent (1955) demonstrated that in mice experimentally infected with $T$. canis larvae commonly migrate to the brain, and he suggested that they may occasionally be responsible for carrying viruses and other micro-organisms to it; and Mochizuki et al. (1954) demonstrated experimentally in mice that $T$. canis larvae in migrating to the brain could carry with them the virus of Japanese B encephalitis. Much important early work on the development of the infection in man was done by Beaver and his associates and is reviewed by Beaver (1962).

\footnotetext{
* Welleome Professor of Clinical Medicine, London School of Hygiene and Tropical Medicine.

† Research Assistant and Honorary Senior Medical Registrar, Hospital for Tropical Diseases, London.

$\ddagger$ Medical Director, Lingfield Hospital School, Lingfield, Surrey.
}

Having devised an antigen for determining the incidence of past toxocaral infection, and having shown that it is suitable for use in man and gives rise neither to significant numbers of falsepositive reactions in those who have not been infected nor to cross-positive reactions in persons infected with other helminths, we decided to try to answer the question whether those who gave a past history of poliomyelitis had been infected with toxocariasis more frequently or less frequently than the apparently healthy population. Conversations were held with several people on diseases the cause of which is at present unknown but which could be produced by the lesions in the brain due to small toxocaral granulomata, and Professor G. Bull suggested that some cases of epilepsy might result from them. It was therefore also decided to attempt to determine whether those with epilepsy had been more often infected with toxocariasis than healthy persons. Brain and Allan (1964) reported encephalitis with convulsions in a patient with toxocariasis, and these convulsions were later followed by many epileptic seizures.

$T$. canis and $T$. cat $i$ are ascarids of which the adults normally inhabit the intestines of dogs and cats respectively. The ova of these worms are passed in the animal's faeces and are infective to man; they develop into larvae which burrow into the human intestinal wall, whence they are taken in blood to a wide variety of organs even though the organ in which they have been most frequently demonstrated is the eye. The larvae, it seems, seldom develop into mature toxocarae in man, only one such instance having been reported prior to the publication in this issue (p. 1583) of the case of Bisseru et al. (1966). The larvae, it appears, usually wander in the tissues till they die and then stimulate granulomatous tissue formation around their disintegrating bodies.

Earlier work (Woodruff and Thacker, 1964) showed that of 300 dogs from the Home Counties $20.7 \%$ were infected with $T$. canis and of 176 cats $22.7 \%$ were infected with $T$. cat $i$, thus 